\title{
SMTP (Stachybotrys microspora triprenyl phenol) enhances clot clearance in a pulmonary embolism model in rats
}

\author{
Weimin $\mathrm{Hu}^{1}$, Ritsuko Narasaki ${ }^{1}$, Naoko Nishimura ${ }^{2}$ and Keiji Hasumi ${ }^{1}{ }^{2 *}$
}

\begin{abstract}
Background: Stachybotrys microspora triprenyl phenols (SMTPs) are a novel family of small molecules that enhance both activation and fibrin-binding of plasminogen. While their effects on fibrinolysis have been characterized in vitro, little is known about their activity in vivo with respect to plasminogen activation and blood clot clearance.

Results: To select a potent SMTP congener for the evaluation of its action in vitro and in vivo, we tested several SMTP congeners with distinct structural properties for their effects on plasminogen activation. As a result, SMTP-7 (orniplabin) was found to have distinguished activity. Several lines of biochemical evidence supported the idea that SMTP-7 acted as a plasminogen modulator. SMTP-7 elevated plasma level of plasmin- $\alpha_{2}$-antiplasmin complex, an index of plasmin formation in vivo, 1.5-fold in mice after the intravenous injections at doses of 5 and $10 \mathrm{mg} \mathrm{kg}^{-1}$. In a rat pulmonary embolism model, SMTP-7 $\left(5 \mathrm{mg} \mathrm{kg}^{-1}\right)$ enhanced the rate of clot clearance $\sim 3$-fold in the absence of exogenous plasminogen activator. Clot clearance was enhanced further by $5 \mathrm{mg} \mathrm{kg}^{-1}$ of SMTP-7 in combination with single-chain urokinase-type plasminogen activator.
\end{abstract}

Conclusions: Our results show that SMTP-7 is a superior plasminogen modulator among the SMTP family compounds and suggest that the agent enhances plasmin generation in vivo, leading to clearance of thrombi in a model of pulmonary embolism.

Keywords: plasminogen, fibrinolysis, thrombolysis, thromboembolism

\section{Background}

The plasminogen/plasmin system plays a central role in blood clot lysis $[1,2]$. Plasminogen is a single-chain glycoprotein consisting of an $\mathrm{N}$-terminal PAN domain, five homologous kringle domains, and a trypsin-like serine protease domain. Plasminogen is converted to the active enzyme plasmin by the specific cleavage of the $\operatorname{Arg}^{561}$ $\mathrm{Val}^{562}$ bond by tissue-type plasminogen activator (t-PA) or urokinase-type plasminogen activator (u-PA). The binding of plasminogen to fibrin and cell surfaces, mediated by kringle domains in plasminogen, localizes fibrinolytic activity on fibrin and cell surfaces [3]. Plasminogen adopts a tight conformation due to an intramolecular interaction between a lysine residue $\left(\right.$ Lys $^{50}$ and/or

\footnotetext{
* Correspondence: hasumi@cc.tuat.ac.jp

'Department of Applied Biological Science, Tokyo Noko University, 3-5-8

Saiwaicho, Fuchu, Tokyo 183-8509, Japan

Full list of author information is available at the end of the article
}

Lys $^{62}$ ) in the PAN domain and a lysine binding site in the fifth kringle domain $[4,5]$. The tight conformation of the plasminogen molecule attenuates its activation and interaction with fibrin and cellular receptors $[3,6]$. Lysine analogs such as 6-aminohexanoic acid bind to lysine binding sites in kringle domains and induce a large-scale conformational change in plasminogen $[7,8]$, facilitating its activation by plasminogen activators. However, lysine analogs inhibit plasminogen binding to fibrin or cell surface receptors and, therefore, inhibit fibrinolysis. Fibrin is not only a substrate of plasmin but also a cofactor of plasminogen activation. Upon binding to fibrin, plasminogen undergoes conformational change to become susceptible to activation [9]. Further, partial degradation of fibrin by plasmin generates $\mathrm{C}$-terminal lysines, resulting in the accumulation of more plasminogen to degrading fibrin to accelerate fibrinolysis.
C Biomed Central

(ㄷ) 2012 Hu et al; licensee BioMed Central Ltd. This is an Open Access article distributed under the terms of the Creative Commons Attribution License (http://creativecommons.org/licenses/by/2.0), which permits unrestricted use, distribution, and reproduction in any medium, provided the original work is properly cited. 
Thus, conformational regulation of plasminogen is implicated in the localization and activation of plasminogen. This mechanism suggests that pharmacological modulation of plasminogen conformation will regulate local plasmin production [10]. We recently identified a series of small-molecule modulators of plasminogen activation. These compounds, which are structurally unrelated to lysine, enhance plasminogen activator-catalyzed plasminogen activation. Unlike lysine analogs, these modulators increase plasminogen-fibrin binding [11]. SMTPs (Stachybotrys microspora triprenyl phenols) and staplabin are the representatives of the "nonlysine-analog" plasminogen modulators. [11-20]. In this paper, we show that SMTP-7 (orniplabin), one of the most potent congeners, increases plasmin generation in vivo and promotes clot clearance in a rat pulmonary embolism model. These activities provide bases of the therapeutic activity of SMTP-7 toward thrombotic cerebral infarction [21-23].

\section{Results}

\section{Activities of the SMTP congeners in vitro}

We assessed structure-activity relationships of SMTPs to select a congener to be studied in detail. SMTP congeners identified so far are roughly classified into two groups. One is the single-unit congener, consisting of the core triprenyl phenol unit and an $N$-linked side-chain, which is a side-chain of an amino acid (Figure 1A). The other group is the two-unit congener, consisting of two core units bridged by a diamine (Figure $1 \mathrm{~A}$ ). Among the 8 congeners tested, two-unit congeners (SMTP-7, -7D, -8, and -8D) were more active than single-unit congeners (SMTP-4D, $-5 \mathrm{D},-6$, and $-6 \mathrm{D}$ ) in enhancing $\mathrm{u}-\mathrm{PA}$-catalyzed plasminogen activation (Figure 1B). $\alpha$-Tocopherol, which has a structure resembling the core unit of SMTP (Figure 1A), was inactive (Figure 1B). To characterize further, 3 additional two-unit congeners, SMTP-9, -30, and -31 (Figure 1A), were synthesized (additional file 1). SMTP-9 and -31, which had two carboxyl groups, were less active than congeners with one carboxyl group (Figure 1B). SMTP-30, which had no carboxyl group, was essentially inactive (Figure 1B). Thus, the number of carboxyl group affects the activity of two-unit SMTP congeners. Based on these results, SMTP-7 was selected for detailed characterization.

\section{Characterization of the action of SMTP-7 in vitro}

SMTP-7 enhanced t-PA-catalyzed plasminogen activation as well as the activation catalyzed by $\mathrm{u}-\mathrm{PA}$ (Figure $2 \mathrm{~A})$. In the kinetic determinations of u-PA-catalyzed plasminogen activation, SMTP-7 markedly increased $V_{\max }$ and slightly decreased $K_{m}$, resulting in a large increase in $k_{\text {cat }}$ (Figure 2B). The increase in plasmin generation was confirmed by SDS-polyacrylamide gel electrophoresis (Figure 2C). Amidolytic activities of $\mathrm{u}$ PA and t-PA were not affected by SMTP-7 (Figure 2D).
While SMTP-7 moderately elevated the activity of plasmin (Figure 2D), the magnitude ( 3-fold) was smaller than that of plasminogen activation ( 100-fold). In sizeexclusion chromatography, the molecular elution time of plasminogen was slightly shortened in the presence of SMTP-7 (Figure 2E), suggesting that an increase in apparent molecular volume was induced by SMTP-7. Taken together, these properties of SMTP-7 are consistent with the idea of a plasminogen modulator, which increases plasminogen activation by affecting the conformational status of plasminogen [10].

\section{SMTP-7 increases plasma Pm-AP level in mice}

To assess plasminogen activation in vivo, we determined the level of Pm-AP as an index of plasmin generation. Pm-AP was determined by fibrinogen zymography, in which human and mouse Pm-AP appeared as lysis bands at $\sim 140$ and $\sim 130 \mathrm{kDa}$, respectively (additional file 2). When SMTP-7 was administered to normal mice ( 5 and $10 \mathrm{mg} \mathrm{kg}^{-1}$, bolus intravenous injections), the level of Pm-AP in plasma was significantly increased $(\sim 1.5$-fold, $P<0.05)$ (Figures $3 \mathrm{~A}$ and $3 \mathrm{~B})$. Both antiplasminogen IgG and anti- $\alpha_{2}$-antiplasmin IgG decreased the intensity of the lysis band, supporting that the lysis band represented Pm-AP (Figure $3 \mathrm{C}$ and additional file 2). These results suggest that SMTP-7 enhances plasmin generation in vivo.

\section{SMTP-7 enhances clot clearance in a rat pulmonary embolism model}

SMTP-7 was evaluated further in a rat pulmonary embolism model, in which animals were injected with small particles of ${ }^{125}$ I-labeled plasma clots. The clots predominantly distributed over the lungs, and its clearance was monitored continually as the decay of radioactivity in the thorax. Based on the effects of SMTP-7 on the Pm-AP accumulation in mice (Figure 3), the dose of $5 \mathrm{mg} \mathrm{kg}^{-1}$ was used. In control animals given saline alone, the clearance of ${ }^{125}$ I-plasma clots occurred slowly $(6.4 \pm 2.8 \%$ per $20 \mathrm{~min})$ (Figure $4 \mathrm{~A})$. The treatment with SMTP-7 (5 mg kg-1, bolus intravenous injection) significantly increased the rate of clot clearance $(19.8 \pm 2.4 \%$ per $20 \mathrm{~min}$ ) (Figure 4A). This increase was comparable to that $(19.8 \pm 4.1 \%$ per $20 \mathrm{~min})$ brought by scu-PA (250 $\mathrm{U} \mathrm{kg}^{-1}$, bolus intravenous injection) (Figure 4B). The combination of SMTP-7 (5 mg kg-1) and scu-PA $\left(250 \mathrm{U} \mathrm{kg}^{-1}\right)$ increased the clot clearance rate to $42.3 \pm$ $4.2 \%$ per 20 min (Figure $4 \mathrm{~B}$ ).

\section{SMTP-7 does not increase bleeding in normal mice}

Effects of SMTP-7 on bleeding and rebleeding were assessed by a tail amputation assay in normal mice. SMTP7 was tested at the pharmacological dose $\left(5 \mathrm{mg} \mathrm{kg}^{-1}\right)$ and a higher dose $\left(30 \mathrm{mg} \mathrm{kg}^{-1}\right)$. Neither a statistically significant 


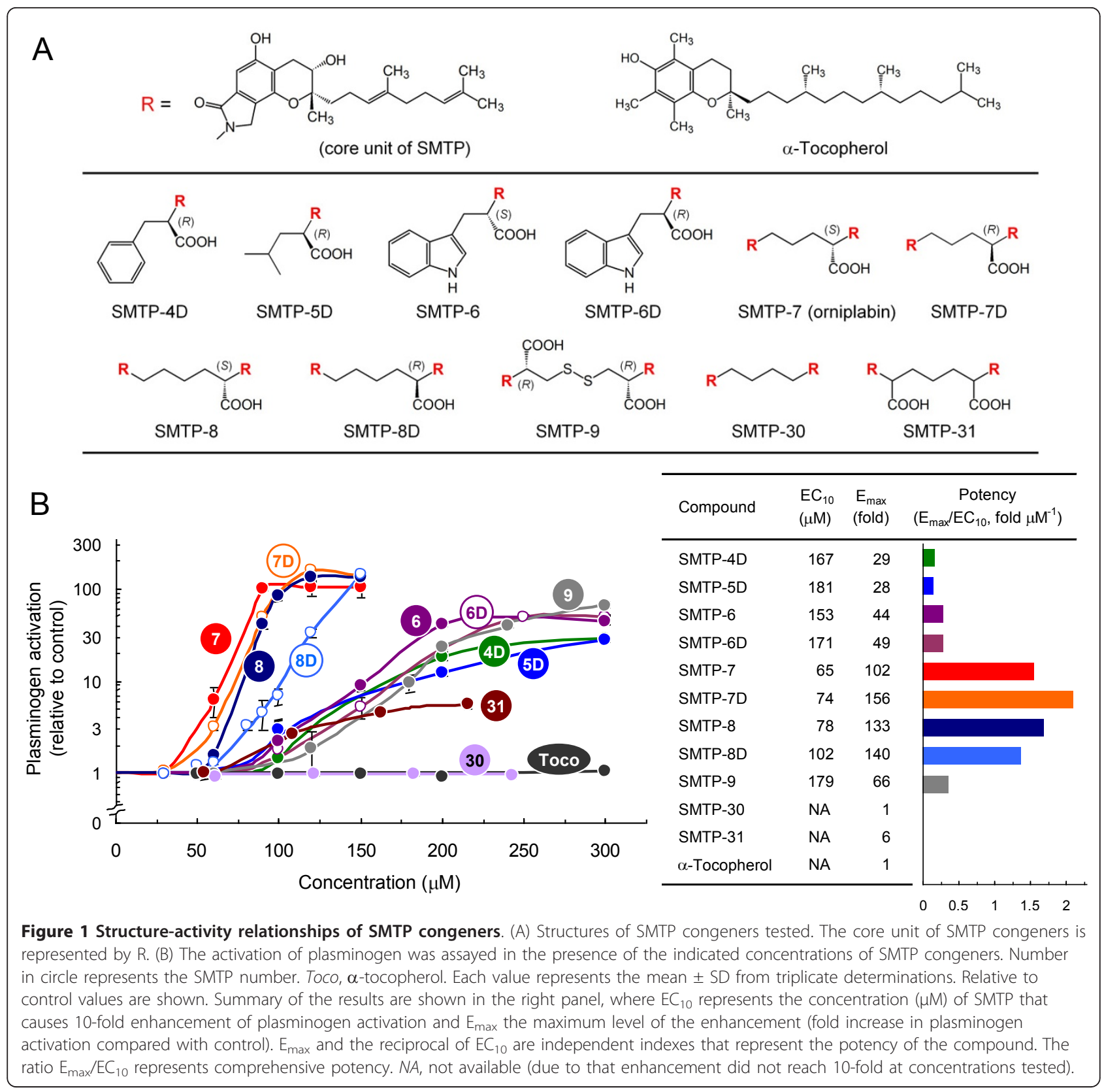

prolongation of bleeding time nor an increase in bleeding volume was observed at both doses (additional file 3 ).

\section{Discussion}

In this study, we demonstrate that SMTP-7, one of the two-unit SMTP congeners, is a plasminogen modulator effective in plasminogen activation and clot clearance. Among the SMTP congeners tested, the two-unit congeners are more active than the single-unit congeners. Of the two-unit congeners tested, analogs with two carboxylic acid groups in the $N$-linked side-chain are weaker than those with one carboxylic acid group. The analog with no carboxylic acid in the $N$-linked sidechain is essentially inactive. Thus, the importance of both the core triprenyl phenol unit and a carboxylic acid group in the $N$-linked side-chain is demonstrated.

The action of SMTP-7 to enhance plasminogen activation conforms to the idea of zymogen modulators [10] based on the following observations: (i) SMTP-7 does not affect the enzymatic activity of $\mathrm{u}-\mathrm{PA}$ and $\mathrm{t}-\mathrm{PA}$ but increases plasminogen activation catalyzed by $\mathrm{u}-\mathrm{PA}$ and t-PA; (ii) SMTP-7 alters conformational status of plasminogen, as evidenced by a change in molecular elution time on analytical size-exclusion chromatography. 

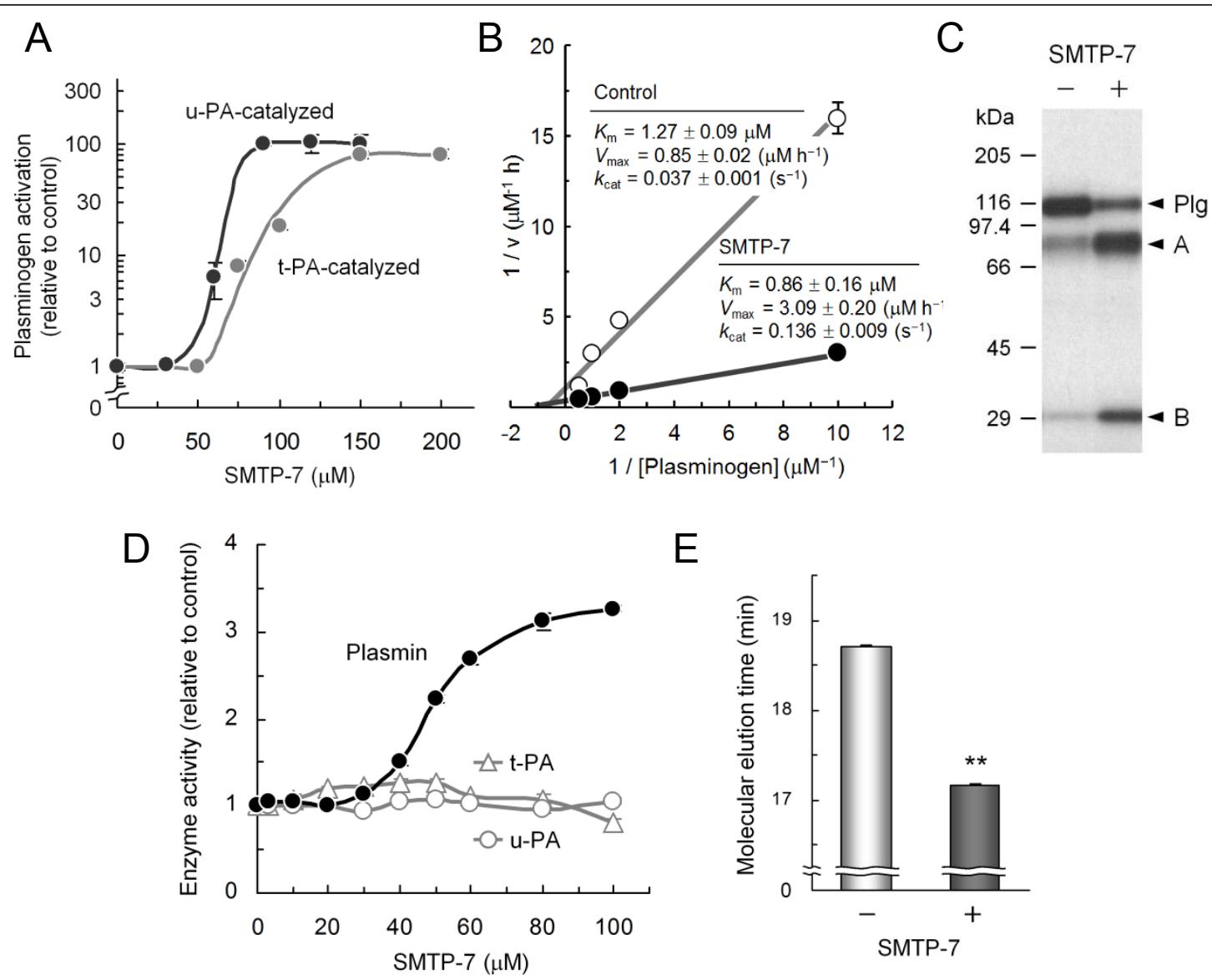

Figure 2 Characterization of SMTP-7 in vitro. (A) Effects on plasminogen activation by t-PA and u-PA. Plasminogen activation was assayed using t-PA or U-PA in the presence of the indicated concentrations of SMTP-7. (B) Kinetic measurements of u-PA-catalyzed plasminogen activation in the presence of SMTP-7 (100 $\mu \mathrm{M})$. Parameters shown were obtained from triplicate determinations. (C) Effect on plasminogen conversion to plasmin. U-PA-catalyzed ${ }^{125}$-plasminogen conversion to plasmin was assayed in the presence or absence of SMTP-7 (100 $\mu$ M). Positions of plasminogen (Plg) and A- and B-chains of plasmin are shown. (D) Effects on amidolytic activities of plasmin, t-PA, and u-PA. Activity of each enzyme was determined using a fluorogenic substrate in the presence of the indicated concentrations of SMTP-7. (E) Size-exclusion chromatography. Alexa 488-labeled plasminogen was eluted in the absence or presence of SMTP-7 (120 $\mu \mathrm{M}) .{ }^{* *}, P<0.05$ by Student's $t$-test. Error bars in panels A, B, D, and E represent SD from triplicate determinations.

SMTP-7 enhances the conversion of plasminogen to the two-chain plasmin. This activity, along with the augmentation of the catalytic activity of plasmin ( 3-fold), results in the apparent increase (up to 100-fold) in plasminogen activation assessed by using a chromogenic substrate. Kinetic data demonstrate that SMTP-7 increases $V_{\max }$ of u-PA-catalyzed plasminogen activation with a slight decrease in $K_{m}$, suggesting that faster turnover of the enzyme is allowed on the SMTP-7-modulated substrate compared with a native substrate.

The administration of SMTP-7 to normal mice resulted in an increase in the level of Pm-AP in plasma. Since plasmin generated in vivo is rapidly inactivated by $\alpha_{2}$-antiplasmin to afford Pm-AP, the level of Pm-AP represents the generation of plasmin in vivo [24]. SMTP-7 does not affect the rate of Pm-AP formation when plasmin is incubated with $\alpha_{2}$-antiplasmin in a purified system (unpublished observation). Thus, the finding that SMTP-7 increases plasma level of Pm-AP in mice suggests that SMTP-7 increases plasminogen activation in vivo. SMTP-7 is effective in promoting the clot clearance in the rat pulmonary embolism model. Compared with the spontaneous clot clearance rate, a 3 -fold increase in the rate is brought by the administration of SMTP-7 at $5 \mathrm{mg} \mathrm{kg}^{-1}$, a dose that is effective in elevating plasma Pm-AP level. The plasma concentration of SMTP-7 at this dose just after the intravenous injection is expected to be $\sim 100 \mu \mathrm{M}$. The rate of clot clearance after the SMTP-7 injection is comparable to the rate brought by the injection of scu-PA at $250 \mathrm{U} \mathrm{kg}^{-1}$. SMTP-7 synergistically enhances the clot clearance in combination with scu-PA. Thus, these properties of the SMTP-7 action in vivo conform to its activity in vitro. 

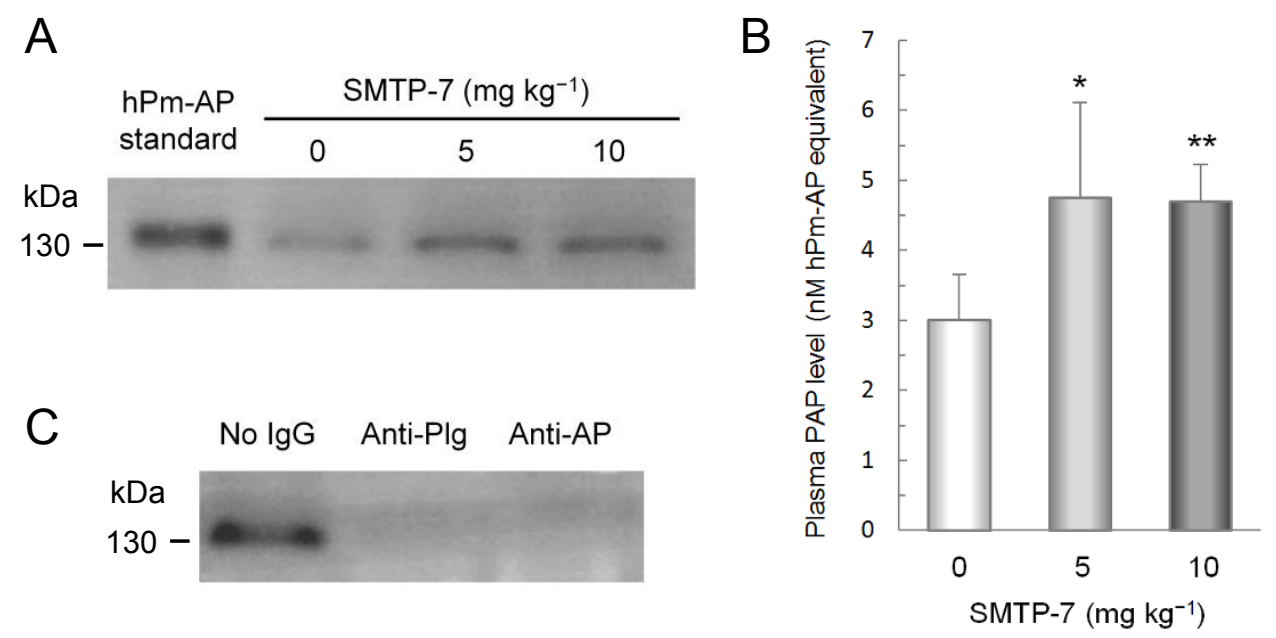

Figure 3 Effect of SMTP-7 on plasma level of Pm-AP in normal mice. Mice were intravenously injected with SMTP-7 at a bolus dose of 5 $\mathrm{mg} \mathrm{kg}^{-1}(n=5)$ or $10 \mathrm{mg} \mathrm{kg}^{-1}(n=5)$. After $60 \mathrm{~min}$, blood was drawn to determine Pm-AP levels in plasma by fibrinogen zymography. Control animals $(n=5)$ received saline. (A) Representative zymogram. Plasmas from 5 animals in each group were combined and aliquots $(2 \mu l)$ of the mixtures were subjected to zymography. Human Pm-AP ( $h P m-A P, 1.7 \mathrm{ng}$ ) was resolved as the standard. (B) The summary of the quantification of Pm-AP. Plasma $(2 \mu \mathrm{l})$ from each of the five mice was independently subjected to zymographic analysis. Data were calibrated by comparing the intensity of each lysis band with that of the standard human Pm-AP. The mean + SD of the data obtained from each animal is shown. ${ }^{*}, P<$ 0.05 and **, $P<0.01$ compared with control by the Dunnett's multiple comparison test. (C) Authenticity confirmation. The mixture of plasma in the $5 \mathrm{mg} \mathrm{kg}^{-1}$ SMTP-7 group was treated with anti-plasminogen IgG (Anti-Plg), anti- $\alpha_{2}$-antiplasmin IgG (Anti-AP), or buffer before the zymographic determination of Pm-AP.

One possible drawback of SMTP-7 may be systemic hyperfibrinolysis and following hemorrhage as that observed in disseminated intravascular coagulation. However, our preliminary studies suggest that these are unlikely to occur at a pharmacological dose $(<10 \mathrm{mg} /$ $\mathrm{kg})$, since bleeding time and rebleeding volume in a mouse tail amputation assay were not changed statistically by the SMTP-7 administration at the pharmacological dose $\left(5 \mathrm{mg} \mathrm{kg}^{-1}\right)$ and a higher dose $\left(30 \mathrm{mg} \mathrm{kg}^{-1}\right)$ (additional file 3). This moderate effect of SMTP-7 on hemorrhage can be explained by that SMTP-7 is a zymogen modulator and its action depends on endogenous plasminogen activators, the availability of which is physiologically regulated.

Plasminogen activators such as recombinant t-PA are important drugs treating acute thrombotic stroke and myocardial infarction $[25,26]$. Recent investigations have demonstrated that SMTP-7 is quite effective in ameliorating thrombotic stroke in models of mouse and gerbil [21-23]. The data in this paper provide bases of the therapeutic activity of SMTP-7 in these models. It is of note that SMTP-7 is effective in the treatment after 3-6 $\mathrm{h}$ of the thrombotic stroke induction, whereas t-PA is ineffective when treated after $3 \mathrm{~h}[21,22]$. The difference in the therapeutic efficacy between SMTP-7 and t-PA is partly explained as that SMTP-7 reduces inflammatory and oxidative responses associated with thrombotic ischemia [22,23,27]. t-PA is reported to induce cerebral inflammation and neuronal cell death by directly interacting with low density lipoprotein receptor-related protein and $N$-methyl-D-aspartate receptor $[28,29]$. In consistent with these observations, hemorrhagic transformation is reduced by SMTP-7, while it is increased by t-PA [22]. Thus, SMTP-7 can be a unique agent that aid in the treatment of thrombotic complications.

\section{Conclusion}

Our results show that SMTP-7 is a superior plasminogen modulator among the SMTP family compounds and suggest that the agent enhances plasmin generation in vivo, leading to clearance of thrombi in a model of pulmonary embolism. These results provide mechanistic bases for the recent findings that SMTP-7 has a profound activity in treating thrombotic stroke in animal models.

\section{Methods \\ Materials}

Human native plasminogen was isolated by lysineSepharose affinity chromatography from frozen citrated plasma. The source of the following reagents were: single-chain u-PA (scu-PA; Thrombolyse ${ }^{\mathbb{B}}$ ) from Mitsubishi Pharma (Osaka, Japan); high molecular weight $\mathrm{u}$ PA $\left(1.47 \times 10^{5} \mathrm{IU} \mathrm{mg}^{-1}\right)$ from JCR Pharmaceuticals (Kobe, Japan); two-chain t-PA $\left(7.0 \times 10^{5} \mathrm{IU} \mathrm{mg}^{-1}\right)$ from Biopool (Umeå, Sweden); sheep anti-mouse plasminogen 

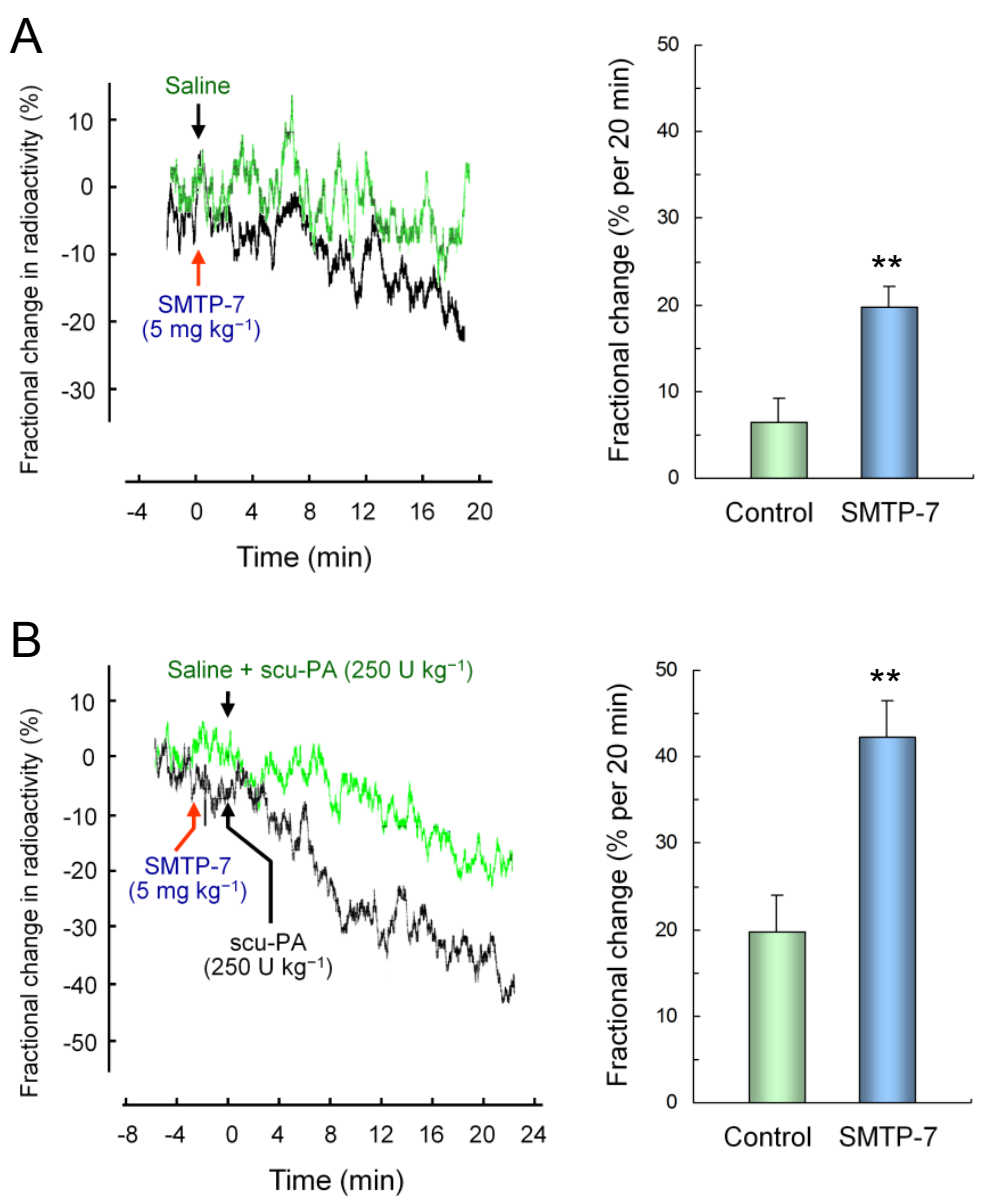

Figure 4 Effect of SMTP-7 on clot clearance in a rat pulmonary embolism model. Rats were injected intravenously with ${ }^{125}$-labeled plasma clots. The clearance of the clots was monitored before and after the treatments with SMTP-7 and/or Scu-PA. (A) SMTP-7 (5 mg kg $\left.{ }^{-1} ; n=6\right)$ was administered intravenously 20 min after the injection of ${ }^{125}$-labeled plasma clot. Control animals $(n=6)$ received saline. Radioactivity over the thorax was monitored (one of the 6 traces is shown in the left panel) and the fractional change in radioactivity was summarized (right panel). (B) SMTP-7 $\left(5 \mathrm{mg} \mathrm{kg}^{-1}\right)$, followed by $250 \mathrm{U} \mathrm{kg}^{-1}$ of scu-PA (Thrombolyse ${ }^{\circledR}$ ), was administered intravenously $\sim 20$ min after the clot injection $(n=6)$. One unit of Thrombolyse ${ }^{\circledR}$ is comparable to $\sim 60 \mathrm{IU}$ of tcu-PA in fibrinolytic activity. In control animals $(n=6)$, scu-PA was given 20 min after the clot injection. Arrow denotes time at which the administration was made. ${ }^{* *}, P<0.01$ compared with control by the Student's $t$-test with normally distributed variables.

IgG from Haematologic Technologies (Essex Junction, VT, USA); rabbit anti-mouse $\alpha_{2}$-antiplasmin IgG from Merdian Life Science (Saco, ME, USA); human fibrinogen and human $\alpha$-thrombin from Sigma (St. Louis, MO, USA); carrier-free $\mathrm{Na}^{125}$ I from Amersham. Radioiodination of fibrinogen and plasminogen was performed using the iodine monochloride method. Upon trichloroacetic acid treatment, more than $95 \%$ of radioactivity in the fibrinogen and plasminogen preparations precipitated with protein. When treated with thrombin, approximately $70 \%$ of the radioactivity in ${ }^{125}$ I-fibrinogen was incorporated into the resulting clots.

\section{SMTP congeners}

All the SMTP congeners used in this study were produced by S. microspora IFO 30018. SMTP-4D, -5D, -6,
$-6 \mathrm{D},-7,-7 \mathrm{D},-8$, and $-8 \mathrm{D}$ were isolated as described previously $[15,17]$. SMTP-9, -30 , and -31 were originally isolated as described in additional file 1 . In experiments in vitro, SMTPs were dissolved directly in buffer A (50 $\mathrm{mM}$ Tris- $\mathrm{HCl}, 100 \mathrm{mM} \mathrm{NaCl}$, and $0.01 \%$ Tween $80, \mathrm{pH}$ 7.4). In animal experiments, SMTP-7 was dissolved in saline by adjusting $\mathrm{pH} \sim 9$ with dilute $\mathrm{NaOH}$.

\section{Assay for plasminogen activation}

Plasminogen activation was determined by measuring the initial velocity of plasmin generation using $\mathrm{H}-\mathrm{Val}-$ Leu-Lys- $p$-nitroanilide (Bachem, Bubendorf, Switzerland), a chromogenic substrate for plasmin. A reaction mixture consisting of $50 \mathrm{nM}$ plasminogen, $50 \mathrm{IU} \mathrm{ml}^{-1} \mathrm{u}$ PA (or $200 \mathrm{IU} \mathrm{ml}^{-1} \mathrm{t}-\mathrm{PA}$ ) and $0.1 \mathrm{mM}$ of the substrate in $50 \mu \mathrm{l}$ of buffer A was incubated in a well of a 96-well 
microplate at $37^{\circ} \mathrm{C}$ for up to $40 \mathrm{~min}$. Absorbance at 405 $\mathrm{nm}$ was measured with an interval of 1 to $2 \mathrm{~min}$. From the slope of the plots of $\mathrm{A}_{405} \mathrm{~nm}$ versus $t^{2}$, the initial velocity of plasmin generation was calculated. In the experiment to determine kinetic parameters, assays were performed with varying concentrations of plasminogen (0.5-2 $\mu \mathrm{M})$ and a fixed concentration of $\mathrm{u}-\mathrm{PA}$ (50 IU $\left.\mathrm{ml}^{-1}\right)$ in the presence or absence of SMTP-7 $(100 \mu \mathrm{M})$. Since SMTP-7 at $100 \mu \mathrm{M}$ enhanced plasmin activity toward H-Val-Leu-Lys-p-nitroanilide by 3.26 -fold (see Figure 2D), this factor was taken into account in the process of the calculation of plasmin generation velocities.

Plasminogen activation was alternatively assayed by determining the conversion to the two-chain form. ${ }^{125} \mathrm{I}$ Plasminogen (100 nM) was incubated with u-PA (50 IU $\mathrm{ml}^{-1}$ ) and aprotinin (100 kallikrein inhibitor units $\mathrm{ml}^{-1}$ ) in buffer $\mathrm{A}$ at $37^{\circ} \mathrm{C}$ for $30 \mathrm{~min}$. The mixture was resolved on SDS-polyacrylamide gel electrophoresis under reducing conditions. The gel was stained with Coomassie Brilliant Blue R-250.

\section{Assay for activities of plasmin, u-PA, and t-PA}

Amidolytic activities of plasmin (10 nM), u-PA (1 IU $\left.\mathrm{ml}^{-1}\right)$, and t-PA $\left(2000 \mathrm{IU} \mathrm{ml}^{-1}\right)$ were determined at $37^{\circ} \mathrm{C}$ in buffer $\mathrm{A}$ using $10 \mu \mathrm{M}$ of $\mathrm{H}$-Val-Leu-Lys-7-amino-4methylcoumarin, $t$-butyloxycarbonyl-Glu-Gly-Arg-7amino-4-methylcoumarin, and succinyl-Phe-Ser-Arg-7amino-4-methylcoumarin, respectively.

\section{Size-exclusion chromatography}

Size-exclusion chromatography was performed using a TSK-Gel G-3000SW column $(7.5 \times 600 \mathrm{~mm}$, TOSOH, Tokyo, Japan) equilibrated with buffer $\mathrm{A}$ in the presence or absence of SMTP-7 (120 $\mu \mathrm{M})$. Plasminogen labeled with Alexa Fluor ${ }^{\circledR} 488$ (Molecular Probes, Eugene, OR, USA) $(10 \mu \mathrm{g})$ was resolved at room temperature at a rate of $1 \mathrm{ml} / \mathrm{min}$. The elution was monitored using a fluorescence detector with an excitation at $495 \mathrm{~nm}$ and an emission at $520 \mathrm{~nm}$.

\section{Animal Experiments}

All of the animal protocols were approved by the institutional animal care committee of Tokyo Noko University. Male Wistar rats and male ICR mice were obtained from Japan SLC (Hamamatsu).

\section{Determination of plasmin- $\alpha_{2}$-antiplasmin complex (Pm- \\ AP)}

Male ICR mice (7 weeks of age) received intravenous SMTP-7 or saline. After $60 \mathrm{~min}$, blood was collected from inferior vena cava in $13 \mathrm{mM}$ sodium citrate. Plasma was rapidly prepared by centrifugation and mixed with one volume of buffer B $(125 \mathrm{mM}$ Tris- $\mathrm{HCl}$,
$\mathrm{pH} 6.8,4 \%(\mathrm{w} / \mathrm{v})$ SDS, 20\% (w/v) glycerol, and 0.004\% (w/v) bromophenol blue). In some experiments, plasma was pretreated with ant-plasminogen IgG $\left(0.6 \mathrm{mg} \mathrm{ml}^{-1}\right)$ or anti- $\alpha_{2}$-antiplasmin IgG $\left(3 \mathrm{mg} \mathrm{ml}^{-1}\right)$ for $30 \mathrm{~min}$ at room temperature before mixing with buffer $B$. The mixture (equivalent to 1-2 $\mu$ l of plasma) was resolved on nonreduced SDS-polyacrylamide gel electrophoresis on a $7.5 \%$ gel containing fibrinogen $\left(2 \mathrm{mg} \mathrm{ml}^{-1}\right)$ at $4^{\circ} \mathrm{C}$. As the standard for the calibration of Pm-AP in plasma samples, $1.7 \mathrm{ng}$ of human Pm-AP (prepared by incubating $120 \mathrm{nM}$ human plasmin and $600 \mathrm{nM}$ human $\alpha_{2}$ antiplasmin for $30 \mathrm{~min}$ at $37^{\circ} \mathrm{C}$ in buffer A) was resolved on the same gel. After electrophoresis, the gel was cut at the position of $\sim 90 \mathrm{kDa}$, and the upper half was washed with Triton X-100 $(2.5 \%, \mathrm{w} / \mathrm{v})$ and incubated in $50 \mathrm{mM}$ Tris- $\mathrm{HCl}, \mathrm{pH} 8.3$, and $100 \mathrm{mM}$ glycine for $60 \mathrm{~h}$ at $37^{\circ} \mathrm{C}$. (The lower half gave a strong lysis band at $\sim 70 \mathrm{kDa}$, possibly due to plasma kallikrein) Gels were stained with Coomassie Brilliant Blue R-250. The lysis zones due to protease activities appeared as unstained bands on a blue background. Human Pm-AP gave a lysis band at $\sim 140 \mathrm{kDa}$, while the mouse counterpart afforded a band at $\sim 130 \mathrm{kDa}$ (additional file 2). The scanned image of the stained gel was reversed for presentations. The band intensity was determined using Scion image. The amounts of Pm-AP in test samples were calibrated by comparing intensities of lysis bands of samples with that of the standard, and data were expressed as human PmAP equivalent ( $\mathrm{nM}$ in plasma).

\section{Preparation of ${ }^{125} \mathrm{I}$-plasma clot particles}

Platelet-poor plasma from male Wistar rats was mixed with ${ }^{125}$ I-fibrinogen $\left(139 \mu \mathrm{g} \mathrm{ml}^{-1}, \sim 2.5 \mathrm{MBq}\right)$ and $\alpha$ thrombin $\left(1 \mathrm{IU} \mathrm{ml} l^{-1}\right)$ in the presence of $44 \mathrm{mM} \mathrm{CaCl}_{2}$. After incubation at $37^{\circ} \mathrm{C}$ for $120 \mathrm{~min}$, the resulting plasma clot was washed thrice with saline and powdered in a mortar under liquid nitrogen, followed by homogenization 4 strokes in $2.7 \mathrm{ml}$ saline using a Potter Elvehjem homogenizer with a Teflon pestle $(13-\mathrm{mm}$ in diameter). The suspension was left at room temperature for $30 \mathrm{~min}$, and the resulting precipitates were homogenized again. This operation was repeated once more. The combined homogenates were settled for $30 \mathrm{~min}$, and the resulting supernatant was centrifuged at $20 \times \mathrm{g}$ for $3 \mathrm{~min}$ to obtain pellet consisting of clot particles of $10-100 \mu \mathrm{m}$ in diameter.

\section{Measurement of clot clearance in the lungs}

Male Wistar rats weighing $\sim 120 \mathrm{~g}$ were kept at $22^{\circ} \mathrm{C}$ with normal chaw for 1-7 days before the use in experiments. Rats were anesthetized with urethane and chloralose (750 and $65 \mathrm{mg} \mathrm{kg}^{-1}$, respectively, i.p.), and a probe (equipped with a $10-\mathrm{mm}$ collimator) of a model TCS$163 \mathrm{NaI}$ scintillation survey monitor (Aloka, Tokyo, 
Japan) was placed above the thorax. A suspension of ${ }^{125}$ I-plasma clot particles $\left(75 \mu \mathrm{kg}^{-1} ; \sim 1.2 \times 10^{7} \mathrm{~Bq}\right.$ per animal) was injected simultaneously with heparin (165 units $\left.\mathrm{kg}^{-1}\right)$ and $\mathrm{NaI}\left(3.3 \mathrm{mg} \mathrm{kg}^{-1}\right)$ into a caudal vein. The ${ }^{125}$ I-plasma clots predominantly distributed over the lungs [30], and radioactivity over the thorax was measured continually. Saline alone $(0.5 \mathrm{ml}$ per animal), saline containing SMTP-7 (5 mg kg-1), scu-PA $\left(250 \mathrm{U} \mathrm{kg}^{-1}\right)$, or both SMTP-7 and scu-PA was intravenously injected $\sim 20$ min after the embolization. The monitoring of radioactivity was continued further for $\sim 20 \mathrm{~min}$. The fractional change in radioactivity during $20 \mathrm{~min}$ after the treatments represented the rate of clot dissolution.

\section{Bleeding and rebleeding in mice}

The measurement of bleeding time and rebleeding volume (secondary oozing from the bleeding time wounds) were performed using male ICR mice (6 weeks of age) as described previously [31]. Briefly, mice were anesthetized with $60 \mathrm{mg} \mathrm{kg}^{-1}$ pentobarbital intraperitoneally and given bolus injection of 5\% mannitol ( $5 \mathrm{ml}$ $\mathrm{kg}^{-1}$ ) or SMTP-7 (5 and $30 \mathrm{mg} \mathrm{kg}-1$ ) in 5\% mannitol via a tail vein. Five minutes after the administration, a 5$\mathrm{mm}$ tail segment was amputated with a razor blade. The tail was immersed immediately in prewarmed saline at $37^{\circ} \mathrm{C}$, and the time required to stop visual spontaneous bleeding was determined. To evaluate rebleeding, the tail was then immersed in another 4-mL prewarmed saline $\left(37^{\circ} \mathrm{C}\right)$ containing $14 \mathrm{mM}$ trisodium citrate for 60 min. Red blood cells were collected and lysed in water to measure absorbance at $490 \mathrm{~nm}$, from which blood loss by rebleeding was calculated.

\section{Additional material}

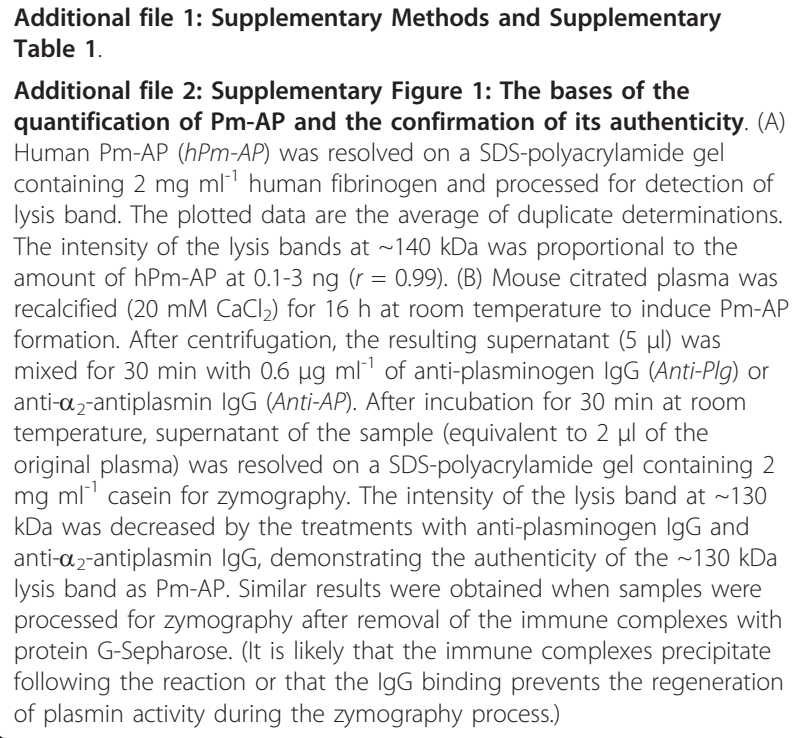

Additional file 3: Supplementary Figure 2: Bleeding and rebleeding following SMTP-7 administration in mice. (A) Bleeding time in mice was determined after an intravenous administration of 5\% mannitol (Control) or SMTP-7 (5 and $30 \mathrm{mg} \mathrm{kg}^{-1}$ ) dissolved in the vehicle. (B) Following the determination of bleeding time, the mice were subjected to the measurement of rebleeding. The mean $+\mathrm{SD}(n=7$ for control and $5 \mathrm{mg} \mathrm{kg}^{-1}$ groups and $n=5$ for $30 \mathrm{mg} \mathrm{kg}^{-1}$ group) was shown. There was no statistical difference between any groups with respect to both bleeding time and rebleeding volume as assessed by the TukeyKramer test.

\section{List of abbreviations}

t-PA: tissue-type plasminogen activator; u-PA: urokinase-type plasminogen activator; scu-PA: single-chain urokinase-type plasminogen activator; Pm-AP: plasmin-a ${ }_{2}$-antiplasmin complex.

\section{Acknowledgements}

We thank Keiko Hasegawa and Haruki Koide for the preparation of SMTP compounds. Blood plasma for the isolation of plasminogen was donated by the Japanese Red Cross Society, Tachikawa. This study was financially supported by grants from the Japan Society for the Promotion of Science, the Japan Science and Technology Agency, and the New Energy and Industrial Technology Development Organization, Japan.

\section{Author details}

'Department of Applied Biological Science, Tokyo Noko University, 3-5-8 Saiwaicho, Fuchu, Tokyo 183-8509, Japan. ${ }^{2}$ Research and Development Division, TMS Co., Ltd., 1-32-1-102 Fuchucho, Fuchu, Tokyo 183-0055, Japan.

\section{Authors' contributions}

WH carried out the animal studies. RN carried out the biochemical studies. $\mathrm{NN}$ performed the ex vivo studies and the bleeding assays. KH participated in the design and coordination of the study and drafted the manuscript. All authors read and approved the final manuscript.

\section{Authors' information}

HW is currently a Professor, Weifang Medical University, Shangdong, China. RN is currently a post doc fellow at W. M. Keck Center for Transgene Research, University of Notre Dame, IN, USA. NN is a research scientist of TMS Co., Ltd. KH is a Professor, Department of Applied Biological Science, Tokyo Noko University, and President of TMS Co., Ltd.

\section{Competing interests}

The authors declare that they have no competing interests.

Received: 20 August 2011 Accepted: 9 January 2012

Published: 9 January 2012

\section{References}

1. Castellino FJ, Ploplis VA: Structure and function of the plasminogen/ plasmin system. Thromb Haemost 2005, 93:647-654.

2. Rijken DC, Lijnen HR: New insights into the molecular mechanisms of the fibrinolytic system. J Thromb Haemost 2008, 7:4-13.

3. Hajjar KA, Nachman RL: Endothelial cell-mediated conversion of Gluplasminogen to Lys-plasminogen. Further evidence for assembly of the fibrinolytic system on the endothelial cell surface. J Clin Invest 1988, 82:1769-1778.

4. Cockell CS, Marshall JM, Dawson KM, Cederholm-Williams SA, Ponting CP: Evidence that the conformation of unliganded human plasminogen is maintained via an intramolecular interaction between the lysine-binding site of kringle 5 and the N-terminal peptide. Biochem J 1998, 333:99-105.

5. An SS, Carreño C, Marti DN, Schaller J, Alberico F, Llinas M: Lysine-50 is a likely site for anchoring the plasminogen $\mathrm{N}$-terminal peptide to lysinebinding kringles. Protein Sci 1998, 7:1960-1969.

6. Christensen U, Molgaard L: Stopped-flow fluorescence kinetic studies of Glu-plasminogen. Conformational changes triggered by $\mathrm{AH}$-site ligand binding. FEBS Lett 1991, 278:204-206. 
7. Urano T, Chibber BA, Castellino FJ: The reciprocal effects of epsilonaminohexanoic acid and chloride ion on the activation of human [Glu1] plasminogen by human urokinase. Proc Natl Acad Sci USA 1987, 84:4031-4034

8. Marshall JM, Brown AJ, Ponting CP: Conformational studies of human plasminogen and plasminogen fragments: evidence for a novel third conformation of plasminogen. Biochemistry 1994, 33:3599-3606.

9. Thorsen $\mathrm{S}$ : The mechanism of plasminogen activation and the variability of the fibrin effector during tissue-type plasminogen activator-mediated fibrinolysis. Ann N Y Acad Sci 1992, 667:52-63.

10. Hasumi K, Yamamichi S, Harada T: Small molecule modulators of the zymogen activation in the fibrinolytic and coagulation systems. FEBS $J$ 2010, 277:3675-3687.

11. Shinohara C, Hasumi K, Hatsumi W, Endo A: Staplabin, a novel fungal triprenyl phenol which stimulates the binding of plasminogen to fibrin and U937 cells. J Antibiot 1996, 49:961-966.

12. Takayasu R, Hasumi K, Shinohara C, Endo A: Enhancement of fibrin binding and activation of plasminogen by staplabin through induction of a conformational change in plasminogen. FEBS Lett 1997, 418:58-62.

13. Kohyama T, Hasumi K, Hamanaka A, Endo A: SMTP-1 and -2, novel analogs of staplabin produced by Stachybotrys microspora IFO30018. J Antibiot 1997, 50:172-174.

14. Hasumi K, Ohyama S, Kohyama T, Ohsaki Y, Takayasu R, Endo A: Isolation of SMTP-3, $-4,-5$ and -6 , novel analogs of staplabin, and their effects on plasminogen activation and fibrinolysis. J Antibiot 1998, 51:1059-1068.

15. Hu W, Ohyama S, Hasumi K: Activation of fibrinolysis by SMTP-7 and -8 , novel staplabin analogs with a pseudosymmetric structure. J Antibiot 2000, 53:241-247.

16. Hu W, Narasaki R, Ohyama S, Hasumi K: Selective production of staplabin and SMTPs in cultures of Stachybotrys microspora fed with precursor amines. J Antibiot 2001, 54:962-966.

17. Hu W, Kitano $Y$, Hasumi K: SMTP-4D, -5D, -6D, -7D and -8D, a new series of the non-lysine-analog plasminogen modulators with a D-amino acid moiety. J Antibiot 2003, 56:832-837.

18. Ohyama S, Harada T, Chikanishi T, Miura Y, Hasumi K: Nonlysine-analog plasminogen modulators promote autocatalytic generation of plasmin (ogen) fragments with angiostatin-like activity. Eur J Biochem 2004, 271:809-820.

19. Hasumi K, Hasegawa K, Kitano Y: Isolation and absolute configuration of SMTP-0, a simplest congener of the SMTP family nonlysine-analog plasminogen modulators. J Antibiot 2007, 60:463-468.

20. Hasegawa K, Koide H, Hu W, Nishimura N, Narasaki R, Kitano Y, Hasumi K: Structure-activity relationships of fourteen new congeners of the SMTP plasminogen modulator. J Antibiot 2010, 63:589-593.

21. Hashimoto $T$, Shibata $K$, Nobe $K$, Hasumi $K$, Honda $K$ : A novel embolic model of cerebral infarction and evaluation of SMTP-7, a novel fungal triprenyl phenol metabolite. J Pharmacol Sci 2010, 114:41-49.

22. Shibata K, Hashimoto T, Nobe K, Hasumi K, Honda K: A novel finding of a low-molecular-weight compound, SMTP-7, having thrombolytic and anti-inflammatory effects in cerebral infarction of mice. N-S Arch Pharmacol 2010, 382:245-253

23. Miyazaki T, Kimura Y, Ohata H, Hashimoto T, Shibata K, Hasumi K, Honda K: Distinct effects of tissue-type plasminogen activator and SMTP-7 on cerebrovascular inflammation following thrombolytic reperfusion. Stroke 2011, 42:1097-1104.

24. Chandler WL, Alessi MC, Aillaud MF, Vague P, Juhan-Vague I: Formation, inhibition and clearance of plasmin in vivo. Haemostasis 2000, 30:204-218.

25. Campbell J, Hilleman D: Recombinant peptides in thrombolysis. Semin Thromb Hemost 2010, 36:529-536.

26. Collen D, Lijnen HR: Thrombolytic agents. Thromb Haemost 2005 93:627-630.

27. Shibata K, Hashimoto T, Nobe K, Hasumi K, Honda K: Neuroprotective mechanisms of SMTP-7 in cerebral infarction model in mice. N-S Arch Pharmacol 2011, 384:103-108.

28. Yepes M, Roussel BD, Ali C, Vivien D: Tissue-type plasminogen activator in the ischemic brain: more than a thrombolytic. Trends Neurosci 2009, 32:48-55.

29. Suzuki Y, Nagai N, Yamakawa K, Kawakami J, Lijnen HR, Umemura K: Tissuetype plasminogen activator (t-PA) induces stromelysin-1 (MMP-3) in endothelial cells through activation of lipoprotein receptor-related protein. Blood 2009, 114:3352-3358.
30. Kikuchi T, Hasumi K: Enhancement of plasminogen activation by surfactin C: augmentation of fibrinolysis in vitro and in vivo. Biochim Biophys Acta 2002, 1596:234-245.

31. Suzuki Y, Nagai N, Collen D: Comparative effects of microplasmin and tissue-type plasminogen activator (tPA) on cerebral hemorrhage in a middle cerebral artery occlusion model in mice. J Thromb Haemost 2004, 2:1617-1621.

doi:10.1186/1477-9560-10-2

Cite this article as: Hu et al:: SMTP (Stachybotrys microspora triprenyl phenol) enhances clot clearance in a pulmonary embolism model in rats. Thrombosis Journal 2012 10:2.

\section{Submit your next manuscript to BioMed Central and take full advantage of:}

- Convenient online submission

- Thorough peer review

- No space constraints or color figure charges

- Immediate publication on acceptance

- Inclusion in PubMed, CAS, Scopus and Google Scholar

- Research which is freely available for redistribution

Submit your manuscript at www.biomedcentral.com/submit
Biomed Central 